\title{
A expansão escravista da plantagem cafeeira e o movimento demográfico na província de São Paulo. 1850-1888
}

The slavery expansion of coffee plantations and the demographic movement in the São Paulo province. 1850-1888

La expansión esclavista de las plantaciones cafeteras y el movimiento demográfico en la provincia de San Pablo. 1850 - 1888.

L'expansion esclavagiste des plantations de café et les mouvements

démographiques dans la province de São Paulo. 1850-1888

\section{Pedro Guimarães Pimentel}

\section{(2) OpenEdition}

Journals

Edição electrónica

URL: http://journals.openedition.org/espacoeconomia/3494

DOI: $10.4000 /$ espacoeconomia.3494

ISSN: 2317-7837

\section{Editora}

Núcleo de Pesquisa Espaço \& Economia

Refêrencia eletrónica

Pedro Guimarães Pimentel, « A expansão escravista da plantagem cafeeira e o movimento demográfico na província de São Paulo. 1850-1888 », Espaço e Economia [Online], 13 | 2018, posto online no dia 28 novembro 2018, consultado o 02 maio 2019. URL : http://journals.openedition.org/ espacoeconomia/3494; DOI : 10.4000/espacoeconomia.3494

Este documento foi criado de forma automática no dia 2 Maio 2019

(c) NUPEE 


\section{A expansão escravista da plantagem cafeeira e o movimento demográfico na província de São Paulo. 1850-1888}

The slavery expansion of coffee plantations and the demographic movement in the São Paulo province. 1850-1888

La expansión esclavista de las plantaciones cafeteras y el movimiento

demográfico en la provincia de San Pablo. 1850 - 1888.

L'expansion esclavagiste des plantations de café et les mouvements

démographiques dans la province de São Paulo. 1850-1888

\section{Pedro Guimarães Pimentel}

1 ano de 1850 é o divisor de águas de um processo histórico. $O$ golpe dado pela proibição oficial do tráfico foi prontamente respondido com dois contragolpes: a Lei Eusébio de Queiroz, ou a Lei de Terras, e, em substituição do tráfico de africanos forçosamente escravizados, a organização do tráfico de europeus pobres "livremente" convencidos. Certo é que o segundo tráfico somente ganhou vultos significativos quando a escravidão foi abolida. No entanto, seu planejamento e suas formas experimentais foram realizadas com antecedência considerável: era preciso criar um contingente populacional capaz de reduzir drasticamente os salários, tornando compensatória a substituição do trabalho servil pelo livre.

2 Se nos Estados Unidos o fim do tráfico internacional significou a montagem da empresa escravista nacional ${ }^{1}$, em nossas paragens a mentalidade "consular" da elite econômica ainda compreendia a força de trabalho como um "meio de produção", podendo gastá-la como se gasta o carvão:

O povo, primeiro, era o gentio pagão (...). Depois, foi a negraria escrava importada como uma força energética que se queimava como um carvão humano nas minas e 
nas plantações para produzir o que não comiam nem queriam, mas sim o que dava

lucro ao amo e senhor. (RIBEIRO, D. 1986, pp.78-79)

3 A cessação do tráfico internacional acarretou a promoção do tráfico interprovincial. E no momento em que este também viesse a se exaurir, a empresa imigrantista já teria se consolidado: o esgotamento físico concorria para a eliminação real da força de trabalho, obrigando à maiores investidas de busca através do tráfico ilegal (e a consequente elevação do preço), de outro, a campanha abolicionista se avolumava com a luta pela liberdade através das alforrias individualmente conquistadas e das revoltas coletivas, do aquilombamento ou simplesmente da fuga para a cidade.

4 A segunda metade do século XIX presenciou um movimento do contingente populacional brasileiro e das relações jurídicas da força de trabalho somente capazes de se tornarem inteligíveis quando colocados diante das transformações que o advento das sociedades imperialistas industriais provocaram não somente em seus próprios territórios, mas também em seus contrapontos evolutivos, as sociedades neocoloniais (RIBEIRO, 1983). Com efeito, é evidente que a classe dominante brasileira optou reiteradamente em fazer o país cumprir o papel de produtor de gêneros agrícolas que atendessem aos mecanismos da industrialização europeia. Para isto, investiu e reforçou a escravidão até onde foi possível suportar.

No centro desta expansão da segunda escravidão está a retomada do trabalho escravo como uma força produtiva (Massensklaverei), isto é, a concentração em massa de trabalhadores escravizados dedicados para a produção de insumos e a criação de novas áreas produtivas a fim de satisfazer a crescente demanda do mercado mundial por gêneros tropicais e semitropicais gerada pela industrialização e urbanização. (TOMICH; ZEUSKE, 2008, p.92)

5 Neste trecho, traduzido livremente, do artigo Introduction, the Second Slavery: Mass Slavery, World-Economy, and Comparative Microhistories, Dale Tomich e Michael Zeuske versam sobre aquilo que denominam de "segunda escravidão", um novo momento do apresamento de seres humanos que está relacionado com o avanço das forças produtivas industriais e a demanda por insumos agrícolas. Para tanto, a manutenção e ampliação da escravidão na segunda metade do século XIX contou minimamente com a estruturação de um Estado Nacional (ou um poder local similar, como no caso de Cuba), no qual estavam alocadas as elites escravistas desejosas de manter a dominação socioeconômica que haviam adquirido no período colonial às custas do mesmo trabalho escravizado. Por outro lado, esta "segunda escravidão" precisa ser compreendida não apenas nas características do escravismo colonial brasileiro (café), mas na capacidade de reprodução ampliada desse sistema econômico enquanto modo de produção sui generis também no Sul dos Estados Unidos (algodão) e em Cuba (açúcar) (GORENDER, 1980).

Computa-se nesse período, a abolição do tráfico internacional no Brasil - com a correspondente cessação progressiva do apresamento de trabalhadores na costa africana, tendo a constrição ao trabalho ganhado outros contornos - o processo de expulsão do excedente populacional dos países europeus dependentes (Itália, Espanha e Portugal), além da China, movimento que ficou conhecido como "as grandes ondas de imigração"; a incessante evasão da força de trabalho escravizada - através do aumento das lutas diretas (fugas, aquilombamento, alforrias) e, em menor grau, das leis atenuantes e etapistas (Lei do Ventre Livre, Lei dos Sexagenários) até a abolição completa em 1888, que coincidirá com o avolumar da entrada de trabalhadores europeus no Brasil. 
7 Todo esse processo foi codificado e normatizado tanto interna como externamente. A pressão inglesa, com ações diplomáticas e intervenções diretas como o Bill Aberdeen, provocaria no Império do Brasil uma dupla resposta. A abolição do tráfico internacional e o movimento de emancipação dos trabalhadores escravizados - que era acompanhado de perto pela classe senhorial - se desdobraria em dois processos históricos complementares: a latifundiarização da produção, que tem na Lei de Terras seu marco claro e objetivo, e a criação artificial do excedente populacional capaz de reduzir a remuneração direta ou indireta do trabalhador "livre".

8 A latifundiarização da economia brasileira é resultado da exclusividade do acesso à terra pela compra, a partir da Lei Eusébio de Queiroz, ou Lei de Terras de 1850. Até então, a posse garantia o uso da terra para a produção de subsistência ou para a produção comercial, seja ela acessória ou de plantagem. De imediato, mais do que transformar radicalmente o mercado de terras, a nova legislação "criava um sistema cartorial de registro que tornava quase impraticável a um lavrador pobre legalizar suas terras." (RIBEIRO, D. 2007, p.217) O estudo recente de João Fragoso (2013, pp.101-116) para o município de Paraíba do Sul, na Província do Rio de Janeiro, ilustra esse processo ao mostrar, através do levantamento de hipotecas e inventários registrados no cartório municipal, como, no decorrer da segunda metade do século XIX, cai consideravelmente o número de pequenos plantadores de café em favor do aumento do tamanho das propriedades de um contingente reduzido de barões, representantes da elite cafeeira.

9 Esses pequenos plantadores, antigos proprietários de terras, passam então à condição de moradores ou agregados - muitas vezes permanecendo residindo e plantando no mesmo local - à fazenda que se expandia e estabelecendo uma relação de produção completamente distinta tanto da escravidão quanto do trabalho livre assalariado. Por outro lado, com a ampliação da capacidade produtiva da fazenda, a demanda por trabalhadores aumenta, o que se verifica no fluxo de escravizados das províncias do Nordeste em direção ao Sudeste e na empresa imigrantista. Com o auxílio da tabela construída por Pedro Carvalho de Mello (1978, p.71), observamos que entre 1823 e 1872-73 (período de estabelecimento da nova zona produtiva), com exceção das províncias de Piauí, Ceará e Paraíba que somadas aumentam em torno de 33 mil escravizados - todas as outras perdem trabalhadores escravizados num total de 190.414 o que representa $33,34 \%$ dos 570.966 que detinham anteriormente. Enquanto isso, as principais províncias cafeeiras veem seu plantel aumentado na ordem de 150 mil trabalhadores para o Rio de Janeiro, 110 mil para Minas Gerais e 150 mil para São Paulo.

10 É seguro afirmar que a contagem da população escravizada na matrícula de 1872-73 é o início do fim da escravidão no Brasil. A partir desta data, com a sequência das leis "abolicionistas" e o aumento da revolta dos escravizados bem como as manumissões e compras de alforrias, a porcentagem de trabalhadores escravizados tanto quanto o número absoluto caem drasticamente, como demonstra a última matrícula realizada em 1886-87.

Tabela 1. Evolução da população escravizada no Brasil e nas principais provinciais cafeeiras.

\begin{tabular}{ccccccccc}
\hline Ano & Brasil & Variação & RJ & Variação & MG & Variação & SP & Variação \\
\hline $\mathbf{1 8 2 3}$ & 1.163 .746 & & 150.549 & & 215.000 & & 21.000 & \\
$\mathbf{7 2 / 7 3}$ & 1.548 .632 & $33,07 \%$ & 352.004 & $133,81 \%$ & 336.711 & $56,60 \%$ & 156.612 & $745,77 \%$ \\
$\mathbf{8 6 / 8 7}$ & 723.419 & $-53,28 \%$ & 169.909 & $-51,73 \%$ & 191.952 & $-42,99 \%$ & 107.329 & $-45,91 \%$ \\
\hline
\end{tabular}

Fonte: Adaptado de MELLO, 1978, p.61. 
12 A análise dos dados contidos na tabela indica que o dinamismo exercido pela produção cafeeira, em especial a paulista, além de atrair um quantitativo até então desconhecido de trabalhadores escravizados para a província, garantiu o aumento da produção e funcionou como força centrípeta contra a diminuição da força de trabalho escravizada. Em números, isso significa que, enquanto Rio de Janeiro e Minas Gerais deixam de contar com 182.095 e 158.341 escravizados, respectivamente, São Paulo perde apenas 49.283. Mesmo que, tomadas as províncias isoladas uma das outras, as perdas percentuais se mantenham próximas $(51,73 \%, 42,99 \%$ e $45,91 \%)$, a participação da perda absoluta em relação ao quantitativo total do país em 1886-87 é de 22,06\% para os fluminenses, 19,18\% para os mineiros e apenas $5,97 \%$ para os paulistas. Esses dados comprovam o que Gorender denominou de "lei da população escrava":

Se considerarmos uma população escrava de dimensões dadas, verificamos que, ao invés da criação de uma superpopulação relativa, o mecanismo econômico age tendencialmente no sentido da diminuição absoluta da população escrava e da criação de sua escassez. (...) No terço de século em que o escravismo perdurou após a cessação do tráfico africano, (...) a lei da população escrava impôs o reajuste interno do sistema escravista brasileiro, de tal maneira que as regiões de economia decadente passaram a fornecer escravos às regiões de economia florescente. (...) A consequência inevitável não foi senão o fluxo de escravos das regiões menos prósperas ou decadentes em direção à região mais próspera, ou seja, a região cafeeira. (GORENDER, 1980, pp.320-325)

O incremento do volume da lavoura do café observado no período em debate, dadas as características particulares do escravismo no Brasil - "força energética que se queimava como um carvão" - não se daria exclusivamente pelo uso da força de trabalho escravizada. Data da década de 1850 as primeiras experiências de instalação de colônias e uso de trabalhadores imigrantes, não só em São Paulo, mas em todo o Brasil. Esses trabalhadores, expulsos de suas terras num processo de marginalização causado pela capitalização do meio rural e urbanização desregulada, foram chegando em números cada vez maiores no país, principalmente à medida em que a abolição se aproximava - através das leis etapistas - e com o "aperfeiçoar" dos contratos de locação de serviços - como a Lei de 1879.

Gráfico 1 - Entrada anual de imigrantes no Brasil

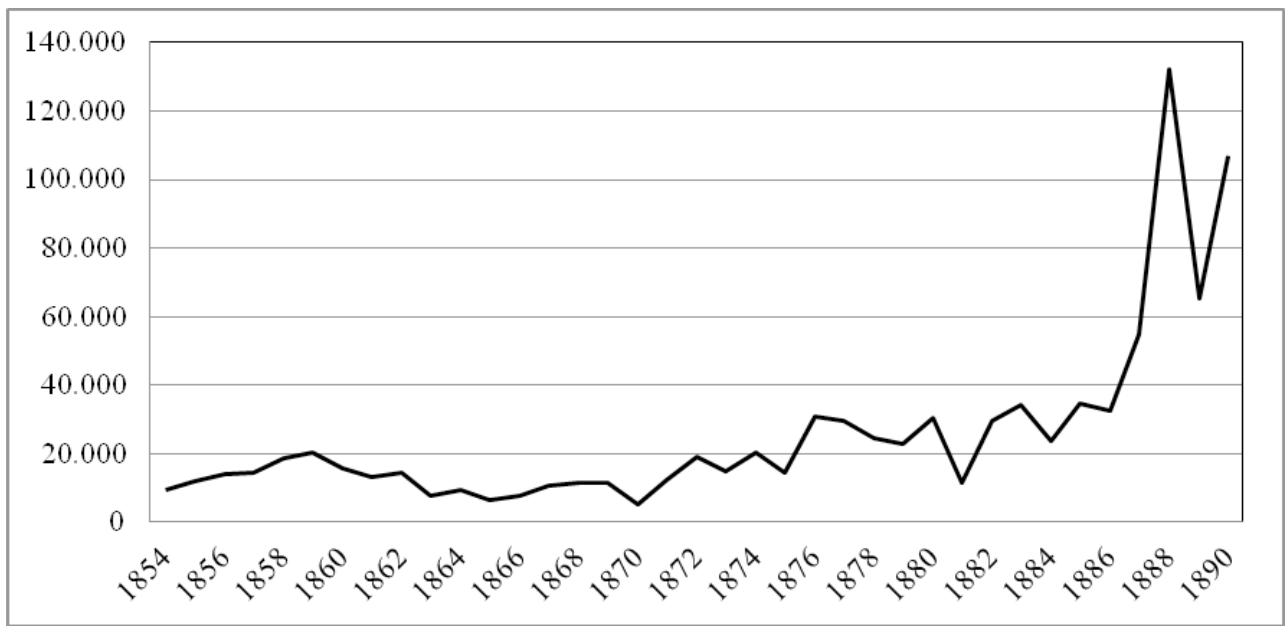

Fonte: IPEADATA. Disponível em: http://www.ipeadata.gov.br/ Obs.: busca por: "imigrantes". 
Essa conta estaria fechada, caso o destino dos trabalhadores imigrantes - que diferente dos escravizados, eram compostos por núcleos familiares, e não homens em sua imensa maioria - fosse exclusivamente a lavoura de café. No entanto, o que os dados abaixo apresentam nos distanciam dessa conclusão precipitada.

Tabela 2. População paulista classificada como “lavradora” no censo de 1872.

\begin{tabular}{lcccc}
\hline $\begin{array}{c}\text { São Paulo - } \\
\mathbf{1 8 7 2}\end{array}$ & Escravizados & Livres & Estrangeiros & $\begin{array}{c}\text { População } \\
\text { Total }\end{array}$ \\
\hline Lavradores & 86.881 & 233.652 & 4.795 & 320.533 \\
Proporção & $55,47 \%$ & $34,32 \%$ & $28,94 \%$ & $38,74 \%$ \\
Total & $\mathbf{1 5 6 . 6 1 2}$ & $\mathbf{6 8 0 . 7 4 2}$ & $\mathbf{1 6 . 5 6 7}$ & $\mathbf{8 2 7 . 3 5 4}$ \\
\hline
\end{tabular}

Fonte: BASSANEZI (b), 1998. Obs.: O Censo Geral do Império de 1872 é a única fonte da Coleção "São Paulo do Passado" que discrimina a população por "profissão".

15 Surpreende o total de somente 16.567 estrangeiros registrados pelo Censo de 1872 na Província de São Paulo, momento em que o país já contava com 250.398 segundo os dados do IPEADATA citados anteriormente ${ }^{2}$. Causa maior espanto, todavia, o quantitativo computado como "lavradores", apenas $28,94 \%$, o que significa, em números absolutos, 4.795 indivíduos frente aos 86.881 escravizados, 55, 47\% do total. Importa-nos observar, sobretudo que São Paulo registra nesse período 233.652 trabalhadores livres anotados como "lavradores". Este fato eleva nosso debate para outro patamar: ao mesmo tempo em que a dinâmica do café paulista e seu "espírito escravista" impede uma queda relativa brusca no total de escravizados se comparado com outras províncias, como Rio de Janeiro e Minas Gerais, também atrai migrantes livres ${ }^{3}$ o que contribui para um crescimento demográfico significativo da província4.

Tabela 3. Evolução demográfica da província de São Paulo

\begin{tabular}{lcccc}
\hline Província de São Paulo & $\mathbf{1 8 5 4}$ & $\mathbf{1 8 7 2}$ & $\mathbf{1 8 8 6}$ & $\begin{array}{c}\text { Variação (72- } \\
86)\end{array}$ \\
\hline Escravizados & & & 106.971 & $-31,69 \%$ \\
$\quad$ Escravizados/Total & $27,95 \%$ & 18,991 & $8,84 \%$ & - \\
\hline Livres & 301.541 & 680.742 & 1.102 .454 & $61,94 \%$ \\
Estrangeiros & 6.757 & 16.567 & 36.821 & $122,25 \%$ \\
$\quad$ Estrangeiros/Livres & $2,24 \%$ & $2,43 \%$ & $3,33 \%$ & - \\
Total & $\mathbf{4 1 8 . 5 3 2}$ & $\mathbf{8 2 7 . 3 5 4}$ & $\mathbf{1 . 2 0 9 . 4 2 5}$ & $\mathbf{4 6 , 1 7 \%}$ \\
\hline
\end{tabular}

Fonte: BASSANEZI, (a), (b) e (c), 1998.

16 Novamente, nos deparamos com alguns elementos inesperados. 0 total de estrangeiros em 1886, apesar de verificar incremento percentual de 122,25 pontos, é de apenas 36.821 . Este valor contrasta com o de 33.310 "imigrantes entrados na Província de São Paulo que gozaram dos favores concedidos pelas leis provinciais, no período decorrido de 1882 a 1887".5 (BASSANEZI (c), 1998, p.101.) Esse aumento não eleva significativamente a participação de estrangeiros no total de trabalhadores livres, ficando abaixo dos 3,5 pontos percentuais. Mesmo assim, o total de trabalhadores livres cresce percentualmente mais do que o total da população. Essa diferença, que é de aproximadamente $40 \mathrm{mil}$ pessoas, pode ser explicada pela combinação de dois fatores: a) permanência de escravizados libertos na província entre 1872 e 1886 e b) continuidade da compra de escravizados de outras províncias. Isso significa que a perda total de escravizados através 
de fugas e alforrias (ou morte) deve ter sido maior do que os 49.641 que a "Tabela 5" informa.

17 A julgar pela proporção de escravizados na lavoura informada pelo Censo de 1872 (Tabela 4), e pelo fato de que as alforrias foram numericamente maiores no meio urbano do que no campo, é de supor (apesar de não termos dados seguros para isso) que a porcentagem de trabalhadores escravizados a serem considerados como "lavradores" em 1886 se elevou. Ao olhar mais de perto os dados fornecidos para cada município paulista, temos uma dimensão mais minuciosa do que estamos discutindo.

Tabela 4. Relação entre escravizados e estrangeiros nos municípios com população estrangeira acima de mil

\begin{tabular}{lcccc}
\hline \multicolumn{1}{c}{18866} & Escravizados & Estrangeiros & Livre & Total \\
\hline São Carlos* & 2.982 & 2.051 & 13.122 & 16.104 \\
Piracicaba & 3.416 & 1.735 & 18.734 & 22.150 \\
Limeira & 2.374 & 1.610 & 13.505 & 15.879 \\
Amparo & 3.524 & 1.540 & 13.801 & 17.325 \\
Araras & 1.623 & 1.341 & 7.896 & 9.519 \\
Botucatu & 820 & 1.188 & 15.165 & 15.985 \\
Descalvado* & 2.182 & 1.124 & 6.075 & 8.257 \\
Pirassununga* & 1.949 & 1.076 & 13.964 & 15.913 \\
Total & $\mathbf{1 8 . 8 7 0}$ & $\mathbf{1 1 . 6 6 5}$ & $\mathbf{1 0 2 . 2 6 2}$ & $\mathbf{1 2 1 . 1 3 2}$ \\
\multicolumn{1}{c}{ /População Total } & $\mathbf{1 5 , 5 7 \%}$ & $\mathbf{1 1 , 4 0 \% * *}$ & $\mathbf{8 4 , 4 3 \%}$ & \\
\hline
\end{tabular}

Fonte: BASSANEZI (c), 1998. * Munícipios do "novo Oeste paulista" (após 1865). ** Estrangeiros/Livres.

18 A tabela acima foi construída tomando por eixo o levantamento daqueles municípios que continham o total de estrangeiros acima de mil pessoas. Nela observamos que com a exceção apenas de Botucatu, todos os outros municípios possuem população escravizada maior do que a estrangeira. Além disso, é notável que dois anos antes da abolição ainda perfaçam um percentual de 15,57 pontos relativos de escravizados frente à população total. Descalvado e São Carlos, municípios destacados como pertencentes ao "novo oeste paulista" possuem taxa relativa de $26,42 \%$ e $18,51 \%$ respectivamente, por exemplo. Por outro lado, da mesma maneira que supomos um incremento da proporção de trabalhadores escravizados no meio rural, é de se imaginar igualmente uma diminuição (obviamente em menor grau) de trabalhadores livres na lavoura, devido à diversificação das atividades produtivas dos quinzes anos finais da escravidão, ainda que contando com seu aumento em números absolutos. Vejamos agora o que acontece quando invertemos o eixo do levantamento e tomamos por base os municípios que possuem população escravizada acima de mil. 
Tabela 5. Relação entre escravizados e estrangeiros nos maiores munícipios escravistas (acima de mil)

\begin{tabular}{lcccc}
\hline \multicolumn{1}{c}{1886 Escravizados } & Estrangeiros & Livres & Total \\
\hline Guaratinguetá & 3.165 & 782 & 22.467 & 25.632 \\
Casa Branca* & 3.004 & 206 & 4.744 & 7.748 \\
Taubaté & 2.668 & 413 & 16.833 & 19.501 \\
Pindamonhangaba & 2.624 & 511 & 15.187 & 17.811 \\
Itatiba & 2.182 & 710 & 7.153 & 9.335 \\
Capivari & 2.003 & 548 & 8.491 & 10.494 \\
Tietê & 1.915 & 253 & 11.057 & 12.972 \\
São José do Barreiro & 1.729 & 148 & 5.341 & 7.070 \\
Ribeirão Preto* & 1.379 & 761 & 9.041 & 10.420 \\
Batatais* & 1.372 & 620 & 18.543 & 19.915 \\
Cunha & 1.141 & 267 & 9.715 & 10.856 \\
Areias & 1.140 & 508 & 5.648 & 6.788 \\
São Simão* & 1.140 & 348 & 5.227 & 6.367 \\
Lorena & 1.129 & 230 & 9.204 & 10.333 \\
Espirito Santo do Pinhal & 1.035 & 704 & 9.480 & 10.515 \\
Total & $\mathbf{2 7 . 6 2 6}$ & 7.009 & $\mathbf{1 5 8 . 1 3 1}$ & $\mathbf{1 8 5 . 7 5 7}$ \\
\multicolumn{1}{c}{ /População Total } & $\mathbf{1 4 , 8 7 \%}$ & $4,43 \% * *$ & $85.13 \%$ & \\
\hline
\end{tabular}

Fonte: BASSANEZI (c), 1998. * Munícipios do "novo Oeste paulista" (após 1865). ** Estrangeiros/Livres.

Tabela 6. Relação entre escravizados e livres nos maiores municípios escravistas (acima de mil)

\begin{tabular}{lccc}
\hline \multicolumn{1}{c}{ 1886 } & Escravizados & Livres & Total \\
\hline Campinas & 9.986 & 31.267 & 41.253 \\
Bananal & 4.182 & 13.472 & 17.654 \\
Rio Claro & 3.304 & 16.829 & 20.133 \\
Mogi-Mirim & 2.300 & 27.918 & 30.218 \\
São João da Boa Vista* & 1.516 & 8.039 & 9.555 \\
Jaú* & 1.384 & 16.957 & 18.341 \\
Jundiai & 1.366 & 8.888 & 10.254 \\
Itu & 1.345 & 14.495 & 15.840 \\
Bragança Paulista & 1.331 & 23.578 & 24.909 \\
Araraquara* & 1.300 & 8.259 & 9.559 \\
Franca* & 1.283 & 23.228 & 24.511 \\
Itapira & 1.129 & 8.580 & 9.709 \\
Total & $\mathbf{3 0 . 4 2 6}$ & $\mathbf{2 0 1 . 5 1 0}$ & $\mathbf{2 3 1 . 9 3 6}$ \\
\hline \multicolumn{1}{c}{ /População Total } & $13,11 \%$ & $86,89 \%$ & \\
\hline
\end{tabular}

Fonte: BASSANEZI (c), 1998. * Munícipios do "novo Oeste paulista" (após 1865). Obs.: Os municípios acima listados não dispunham de informações sobre população estrangeira, por isso estão alocados em tabela distinta.

19 Sem dúvidas, São Carlos, Piracicaba, Limeira, Amparo, Araras, Descalvado e Pirassununga deveriam constar nas duas tabelas, por fazerem parte dos principais municípios escravistas. Além disso, se esses sete municípios se repetem nos eixos propostos, o segundo eixo dispõe uma relação de localidades em que a participação de estrangeiros no total de trabalhadores livres despenca de $11,40 \%$ para $4,43 \%$ (lembrando ainda que os doze municípios da Tabela 8 não dispunham de dados para a população estrangeira). Entretanto, a taxa relativa de escravizados sobre a população total fica em $14,87 \%$ e $13,11 \%$ respectivamente, muito próxima dos $15,57 \%$ observados na Tabela 6 . Alguns munícipios superam em muito a média: é o caso de Campinas com $24,20 \%$, São Simão com $17,90 \%$ e Casa Branca que atinge a notável marca de $38,77 \%$. Abaixo reproduzimos uma tabela elaborada por Jacob Gorender que compara o crescimento da população escravizada com a produção de café. 
Tabela 7. “População Escrava e Produção Cafeeira de Zonas da Província de São Paulo”.

\begin{tabular}{lccccccc}
\hline & \multicolumn{2}{c}{1836} & & $\mathbf{1 8 5 4}$ & & 1886 \\
& $\begin{array}{c}\text { População } \\
\text { Escrava }\end{array}$ & $\begin{array}{c}\text { Sacas de } \\
\text { Café ** }\end{array}$ & $\begin{array}{c}\text { População } \\
\text { Escrava }\end{array}$ & $\begin{array}{c}\text { Sacas de } \\
\text { Café }\end{array}$ & $\begin{array}{c}\text { População } \\
\text { Escrava }\end{array}$ & $\begin{array}{c}\text { Sacas de } \\
\text { Café }\end{array}$ \\
\hline Vale do Paraiba & 24.460 & 127.601 & 33.823 & 684.410 & 43.361 & 518.567 \\
Oeste Antigo & 33.002 & 17.594 & 40.506 & 122.840 & 52.952 & 752.087 \\
Oeste Novo & 3.854 & 2.320 & 20.143 & 76.305 & 67.036 & 1.180 .183 \\
\hline
\end{tabular}

Fonte: Apud GORENDER, 1980, p.562. Nota-se que o somatório final de escravizados alcança 163.349 trabalhadores, número significativamente discrepante do fornecido pelos dados organizados por Maria Silvia Bassanezi. Optamos por não os modificar já que as fontes em que se baseiam são distintas. De qualquer forma, tal discrepância não prejudica, em nosso entender, a análise proposta.

**Os dados coligidos originalmente por Gorender estavam em "arrobas de café". Procedemos à conversão para "sacas de 60kg" de modo a padronizar (de acordo com os dados de exportação) a apresentação de todas as tabelas e gráficos neste trabalho.

Com tudo o que expusemos anteriormente, somos capazes de afirmar, finalmente, que o aumento da produção de café é fruto do aumento do uso da força de trabalho, como atestam os gráficos adiante. Os dados fornecidos por Gorender, presente nas páginas finais de sua obra, serviram para que o autor defendesse a ideia de que mesmo o "oeste paulista", tão afamado pela historiografia liberal como dotado de uma "consciência capitalista" e propulsor do trabalho livre, em verdade, fez uso do trabalhador escravizado até o último momento, ao mesmo tempo em que alavancava a empresa imigrantista. Desse modo, além de atrair para a província o trabalhador imigrante com promessas de ganhos pessoais futuros, também catalisou a força de trabalho escravizada que se desprendia das províncias economicamente decadentes, contribuindo duplamente para o movimento demográfico observado em São Paulo.

Gráficos 2 e 3. Variação da população escravizada e da produção nas zonas cafeeiras paulistas, respectivamente

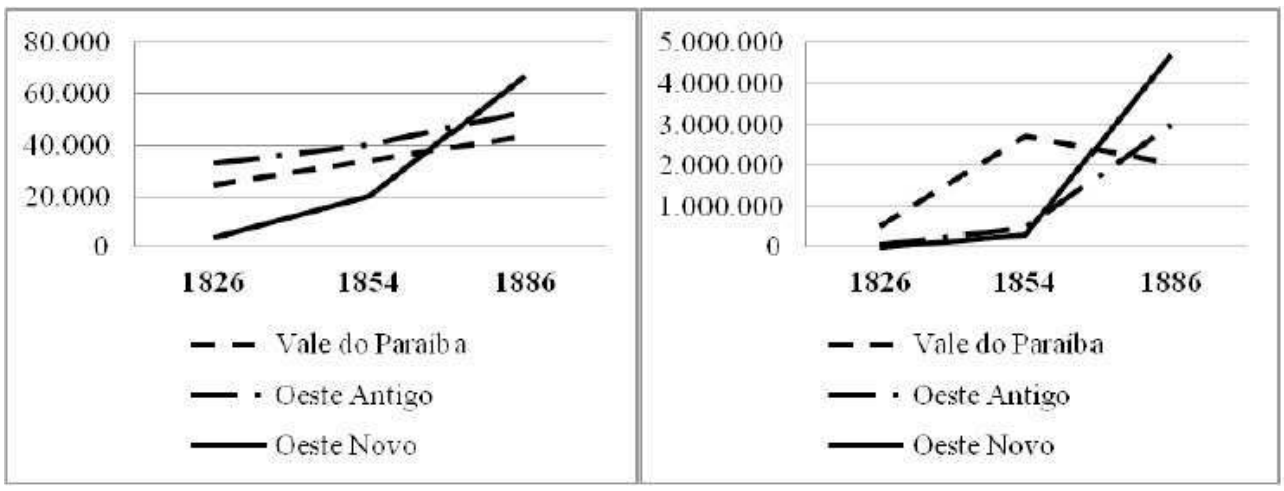

Fonte: Adaptado de GORENDER, 1980, p.562. Em total de trabalhadores e sacas de café.

21 Em resumo, a economia cafeeira da província, em seu processo de modernização reflexa, produziu os seguintes efeitos diretos a) dinamizou o comércio de escravizados, atraindo quantitativo significativo ao mesmo tempo em que contrarrestava a queda absoluta e relativa no processo de desmantelamento do escravismo (gráfico 4), b) transformou pequenos proprietários produtores em agregados, camaradas e moradores, ao mesmo tempo em que atraia migrantes livres de outras províncias, c) através de iniciativas particulares e incentivos provinciais e do governo central, promoveu a imigração 
europeia como forma de solucionar o problema de "braços para a lavoura", que, no entanto, só cumpriu seu objetivo no momento da abolição; tudo isto gerou como resultado o maior crescimento vegetativo relativo entre todas as províncias, fundamentado na presença de trabalhadores "livres".

Gráfico 4. Variação da população escravizada em SP, RJ e MG em números absolutos. ${ }^{6}$

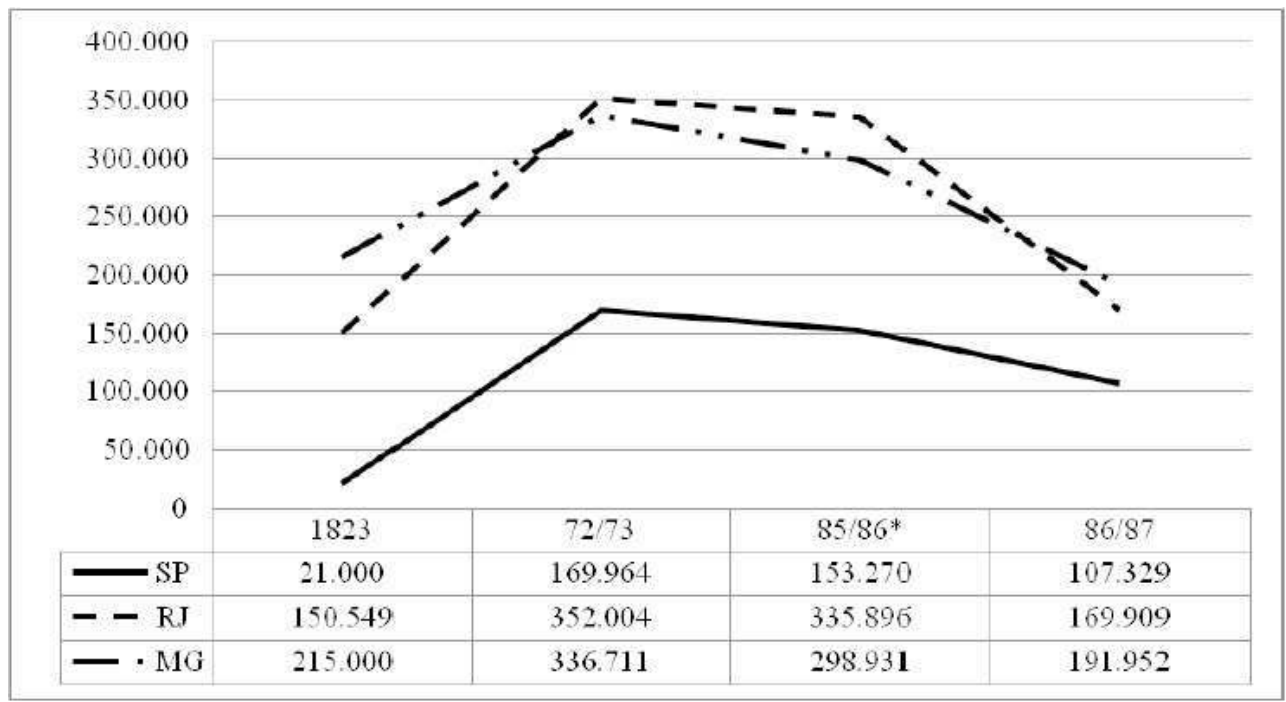

Fontes: MELLO, 1978; SÃO PAULO. * Para Minas Gerais, o ano de referência é a matrícula realizada entre 1884 e 1885. Relatorio apresentado á Assembléa Legislativa Provincial... São Paulo: Typ. a Vapor de Jorge Seckler \& C, 1886; RIO DE JANEIRO. Relatorio apresentado á Assembléa Legislativa Provincial do Rio de Janeiro... Rio de Janeiro: Typ. Montenegro, 1886; MINAS GERAIS. Falla que o exm. sr. dr. Antonio Gonçalves Chaves... Ouro Preto: Typ. do Liberal Mineiro, 1884. 318907

E colaterais: a) o crescimento intensivo da força de trabalho escravizada restaurou na província o fenômeno quilombola como um dos mecanismos de luta entre os trabalhadores escravizados e a classe senhorial (FIABANI, 2012), b) o incremento das fugas e alforrias contribuiu para o crescimento da população livre, especialmente os "livres de cor", como já atestavam os dados do Censo de 1872:

Tabela 8. “Livres de Cor" e escravizados nas principais províncias escravistas

\begin{tabular}{lcccccc}
\hline \multicolumn{1}{c}{1872} & $\begin{array}{c}\text { Livres "de } \\
\text { Cor" }\end{array}$ & Escravos & $\begin{array}{c}\text { Pessoas "de } \\
\text { Cor" }\end{array}$ & Brancos & Total \\
\hline Minas Gerais & 805.967 & 370.459 & 1.176 .426 & 830.987 & $\mathbf{2 . 0 0 7 . 4 1 3}$ \\
Rio de Janeiro & 252.271 & 341.576 & 593.847 & 455.074 & $\mathbf{1 . 0 4 8 . 9 2 1}$ \\
São Paulo & 207.845 & 156.612 & 364.457 & 433.432 & $\mathbf{7 9 7 . 8 8 9}$ \\
Brasil & 4.245 .428 & 1.510 .806 & 5.756 .234 & 3.787 .289 & $\mathbf{9 . 5 4 3 . 5 2 3}$ \\
\hline
\end{tabular}

Fonte: LUNA \& KLEIN, 2010.

Como podemos ver, com exceção apenas do Rio de Janeiro, o número de indivíduos arrolados como "livres de cor" é superior nas demais províncias: pouco mais que o dobro em Minas Gerais - província que já havia vivenciado um período de dinamismo no século anterior - e quase o triplo para o total do país. Dois fatores contribuem para a aparição desses dados. $O$ primeiro diz respeito aos ciclos econômicos que dinamizaram diferentes regiões que, em período de ascensão e auge atraíam a compra de escravizados - além de experimentarem igualmente um incremento na luta pela emancipação - e em períodos de descenso e estagnação a repelia de tal modo que era incapaz também de manter o plantel 
do período anterior. Por outro lado, a contínua luta pela emancipação, protagonizada pelos trabalhadores e trabalhadoras (estas sempre em menor proporção) agia decisivamente para que, rápida ou lentamente, a proporção entre brancos e "de cor" fosse sempre favorável a estes últimos e obrigasse à classe senhorial a constantemente repor seu quantitativo ótimo de produção.

A rigidez da mão-de-obra escrava significa o seguinte: a quantidade de braços de um plantel permanece inalterada apesar das variações da quantidade de trabalho exigida pelas diferentes fases estacionais ou conjunturais da produção. (GORENDER, 1980, p.216) (...) Sendo o escravo uma propriedade valiosa, não deixaria de entrar no cálculo do seu dono o interesse na conservação de sua utilidade produtiva pelo período mais prolongado possível. ${ }^{7}$ (p.320)

Com a apresentação da tabela acima, merece atenção retomarmos rapidamente o cálculo sobre a população classificada como "lavradora" na província de São Paulo em 1872. Se, como mostrado na "Tabela 2" 34,32\% da população livre se dedicava aos trabalhos na lavoura e, supondo a mesma proporção para os "livres de cor", obteremos um quantitativo de 71.333 "livres de cor" no setor produtivo. Somados ainda aos 86.881 escravizados também classificados como "lavradores" - perfazendo $55,47 \%$ do total de trabalhadores escravizados da província - chegaremos, então, ao total de 158.214 "pessoas de cor" alocadas na agricultura - direta ou indiretamente ligadas à plantagem. Por outro lado, já que os 207.845 "livres de cor" reduzem para 433.432 (472.897) o total de brancos (e livres) e, lembrando que temos $34,32 \%$ de lavradores entre os livres - em verdade, alcançamos então 148.754 brancos "lavradores". Se, finalmente, fossemos capazes de discriminar o percentual de brancos proprietários entre os brancos lavradores obteríamos, então, não somente uma dimensão mais exata da participação da população na hierarquia escravista colonial de produção, mas também um perfil étnico dessa hierarquia.

Essa fotografia demográfico-econômica que o Censo de 1872 revelou é, no processo histórico em discussão, o ponto de viragem de um movimento mais amplo que tendeu a aprofundar a contradição fundamental que poria fim ao escravismo colonial: o conflito pela apropriação do sobre-trabalho humano, ou simplesmente a luta de classes que, nesse distinto modo de produção opunha escravizados a senhores.

26 A etapa neocolonial do escravismo, inaugurada pela independência das colônias e vinculada ao processo de industrialização das antigas metrópoles - com exceção da própria Espanha e de Portugal - contou de maneira tardia e reflexa com um dos principais benefícios gerados pelas sucessivas revoluções tecnológicas: a explosão demográfica garantida pela melhoria geral das condições de vida . Como, no entanto, a nova nação era, na verdade, um "Estado escravista" (assunto que retomaremos adiante), na qual não somente as relações de produção estavam consubstanciadas na oposição senhor-escravo, mas também as relações sociais previam a hierarquização pela posse ou não de escravos e a repulsa ao trabalho manual para aqueles que desejavam fazer parte dos "homens bons", essa mesma sociedade teria que lidar, contínua e aceleradamente, com a revolta dos escravizados em sua luta pela emancipação e uso-fruto da própria força de trabalho ${ }^{10}$.

A dinâmica própria do movimento demográfico observado - crescimento vegetativo da população livre (branca e "de cor"), crescimento conflituoso da população livre (fugas, manumissões) e crescimento artificial da população livre (imigração europeia) - impunha o aprofundamento da distinção racial da força de trabalho como única maneira possível de perpetuar a própria estrutura interna da produção, a escravidão. 
Os senhores de escravos do século XIX promoveram novos preceitos políticos, negociaram novas alianças sociais e herdaram, adaptaram e reconfiguraram um contrato racial que atrairia o apoio de importantes grupos de pessoas livres, não escravistas, dessas sociedades. Doutrinas relacionadas à raça, à propriedade e aos interesses nacionais foram defendidas para justificar a posse de escravos e conter os desafios abolicionistas. Da mesma forma que os anteriores, os novos conceitos e estereótipos raciais retratavam os afrodescendentes como necessitados de coerção física e de duras restrições, e os indígenas como dignos apenas de desprezo. (...) Esses homens trabalhavam por uma "civilização" e um "embranquecimento" da base da população, por uma redução na dependência de escravos e pela negação de direitos políticos ativos àqueles que não tivessem propriedades. (BLACKBURN, 2016, p.23-24)

Todavia, com o fim do tráfico internacional e a inauguração da empresa imigrantista solução traficante e colonial para a "demanda de braços para a lavoura" que se tornaria um mecanismo de efeito contrário ao desejado pela classe senhorial, ao aprofundar a contradição do uso da força de trabalho - os plantadores se viram obrigados, enquanto gerentes do Estado, a promulgar leis que garantissem minimamente um contrato o mais livre possível para o trabalhador imigrante, já que estavam impossibilitados de promover uma escravidão branca - daí, mais uma vez, o conteúdo crescentemente racista do fim do escravismo brasileiro. A distância entre a imigração e a escravidão pode ser medida pelo fracasso da parceria, por exemplo, ou pela proibição determinada por alguns governos europeus da vinda de seus cidadãos para o Brasil, ainda nas décadas de 1850 e 1860. É um contrassenso apostar que a elite cafeeira paulista, tão acostumada a traficar gentes e reduzi-las à escravidão, estaria disposta a conceder salários acima dos que estavam "fixados a um nível que oscilava em torno do aluguel do escravo somado ao custo do seu sustento" (GORENDER, 1980, p.568), nos primeiros anos da experiência da colonização. $O$ significado da Lei de Locação de Serviços de 1879 é estarrecedor e auxilia no entendimento do "sumiço" dos estrangeiros que chegavam à São Paulo:

(...) os contratos foram expressamente limitados a seis anos para os trabalhadores nacionais e a cinco anos para o estrangeiros; a dívida inicial do imigrante ficou reduzida à metade do preço da passagem de navio e das 'despesas de instituição' e se proibiram os acréscimos de juros sobre os débitos do locador dos serviços, isto é, o próprio imigrante; proibiu-se a cláusula abusiva da dívida solidária entre turmas de colonos, limitando-se a responsabilidade do colono às dívidas de sua família; na transferência da locação a outro locatário, tornou-se necessária a concordância do locador. A par disso, manteve-se a pena de prisão no caso de abandono do serviço sem pagamento da dívida, bem como o processo sumário de julgamento. (GORENDER, 1980, p.568)

Enquanto perdurou formalmente a escravidão, principalmente na plantagem, qualquer forma de utilização da força de trabalho "livre", seja ela de nacionais ou estrangeiros, esteve fadada a transitar entre maneiras mais ou menos severas de expropriação do trabalhador, fundamentadas todas elas na experiência escravista. A emancipação da força de trabalho - no interior da sociedade escravista - teria como protagonistas, no entanto, os próprios trabalhadores e trabalhadoras escravizados e não os imigrantes. Suas formas de luta são largamente discutidas pelas mais variadas correntes historiográficas e merecem nota apenas alguns aspectos característicos do fim do escravismo colonial.

o primeiro deles diz respeito às manumissões ou alforrias e o significado social dessa forma de emancipação para cada uma das classes envolvidas no conflito. Como observamos, com o fim do tráfico internacional e a não montagem de uma empresa escravista nacional - substituída pela transferência de escravizados das regiões 
decadentes para as ascendentes - a proporção entre trabalhadores livres e escravizados estava tendencialmente determinada a aumentar. $\mathrm{O}$ avanço da luta abolicionista ou autonomista pela emancipação funcionaria então, por um lado, como acelerador desse processo e, por outro, como diretriz política da nova forma de relação de trabalho que deveria suplantar a escravidão. As alforrias, em especial, eram mecanismos essencialmente individuais dessa luta e estavam na esfera da negociação entre escravizado e senhor, fartamente regulados pelo direito escravista. Contudo, não deixavam de representar a assimetria de poder nessa relação.

Tabela 9. Classificação das alforrias em Franca e Campinas no período final da escravidão

\begin{tabular}{cccc}
\hline \multicolumn{1}{c}{ Alforrias } & Onerosas & Gratuitas & Total \\
\hline Franca $\quad(1871-1888)$ & 71 & 42 & $\mathbf{1 1 3}$ \\
Campinas (1879-1888) & 1143 & 1134 & $\mathbf{2 2 7 7}$ \\
\hline
\end{tabular}

Fontes: (1 - Franca) Adaptado de: GOMES, 2008, p.118. (2 - Campinas) Adaptado de: LUNA \& KLEIN, 2010.

31 Das setenta e uma alforrias "onerosas" arroladas no município de Franca, trinta e sete delas estabeleciam compromissos de trabalho pelo liberto até a morte do senhor, isto é, mais da metade das manumissões "não-voluntárias" impediam a imediata libertação do escravizado. Esse tipo de "contrato" é análogo à Lei do Ventre Livre e dos Sexagenários, pois longe de modificar o estatuto jurídico e social do trabalhador, aparentava uma benesse - "lenta, gradual e segura" concedida pela classe senhorial. É evidente que as alforrias também ensejaram outras dinâmicas, como a criação dos Fundos Provinciais de Emancipação, as alforrias coletivas compradas com arrecadação de filantropos, a solidariedade entre libertos e escravizados que se somavam na libertação de cônjuges, filhos e pais, ou que também fundariam suas próprias irmandades com o fim de libertar um número cada vez maior de companheiros, até o ponto de roubos e assassinatos como forma de antecipar o contrato estabelecido... (CHALHOUB, 2011) A vantagem, no entanto, estava do lado dos proprietários e não dos escravizados e, caso não houvesse um incremento na luta pela emancipação, a escravidão duraria até a década de 1920, segundo os cálculos de Rui Barbosa.

Esse incremento, com efeito, se deve à confluência da campanha abolicionista de classe média com o ímpeto dos trabalhadores escravizados em romper de vez com o jugo senhorial. É de fundamental importância, para fins desta discussão, observar a dinâmica perpetrada pela revolta escrava na segunda metade do século XIX e sua relação com a pauta abolicionista. Essa relação é determinante para o fim do escravismo colonial e sua tendencial suplantação pelo capitalismo dependente e não por outro modo de produção.

Décio de Azevedo Saes (1985), em sua tese de livre-docência da Unicamp, sustenta o caráter revolucionário da Abolição. Em termos gerais, Saes dá continuidade ao trabalho de Gorender ao afirmar que o Estado brasileiro imperial era, na verdade, um "Estado escravista". Isto é, de acordo com as formulações de Marx, a um determinado modo de produção deve corresponder um Estado que o sustente e garanta sua continuidade no tempo. Logo, no modo de produção escravista colonial, o Estado deveria ser escravista. Dado que a passagem de um modo a outro deve também corresponder à reorganização do Estado, então o evento da Abolição - que logrou pôr fim ao regime jurídico da escravidão - é um processo revolucionário, o único ocorrido no Brasil, no pensamento do autor. 
Enquanto a massa dos trabalhadores escravizados promovia a luta direta pela emancipação, parte da classe média urbana(izada) dirigia politicamente o processo abolicionista. 0 exemplo mais fidedigno desse processo é a mudança de estatuto que o aquilombamento sofreu nos anos finais da escravidão, principalmente na Província de São Paulo. De estratégia, passou à tática:

O movimento abolicionista de classe média não teve como objetivo estratégico a formação de comunidades negras que restaurassem um modo de vida tribal ou reproduzissem, em pequena escala, as relações entre senhores e escravos. Seu objetivo (...) foi expressão da ideologia jurídica burguesa: a classe média abolicionista queria "libertar" todos os trabalhadores escravos para que os membros de todas as classes sociais - "indivíduos" - acedessem igualmente à condição de sujeitos de direitos (isto é, "cidadãos"). (...) Nesse novo quadro, marcado pela articulação entre o movimento abolicionista de classe média e a revolta escrava, o quilombo (comunidade negra isolada, à parte) deixou de ser o objetivo estratégico da revolta escrava, convertendo-se em objetivo puramente tático. (SAES, D. 1985, pp.277-278)

O fim último da campanha abolicionista não era a emancipação total do trabalho, senão a sua gradual substituição por um modelo mais moderno, o "trabalho livre" tão experimentado nas nações civilizadas da Europa e que teria garantido o desenvolvimento das forças produtivas dessas nações. $O$ golpe (ou a contrarrevolução) republicano e a promulgação da Constituição de 1891 poriam fim às pretensões mais radicais da massa escravizada ao apagar qualquer possibilidade de reforma agrária e colocariam na ordem do dia o erguimento de um "Estado burguês". É este Estado burguês que teria a tarefa de implementar o capitalismo enquanto modo de produção - dependente - no Brasil.

Com efeito, o significado social da emancipação era distinto para os distintos agentes sociais. Enquanto que para a população submetida à escravidão, a liberdade significava o fim da submissão ao senhorio e o "viver por si" na cidade (ou mesmo nas fazendas) ou o retorno a condições pregressas de vida camponesa (como verifica-se na historicidade dos quilombos), para o movimento urbano-popular que lutou pela Abolição, no qual incluíamse libertos e brancos livres (pobres ou pertencentes à setores intermediários e mesmo dominantes), o fim da escravidão deveria pôr o Brasil nos trilhos do progresso, rumo às nações adiantadas - ainda que mantendo sua vocação agrária... Finalmente, para os plantadores, expressava a urgência de arrolar um mecanismo alternativo de coerção ao trabalho que, definitivamente, ainda teria caráter formal (e não real) de subsunção ao capital - por isso a experiência do colonato nas fazendas paulistas.

No que diz respeito às possibilidades de mobilidade social e de acesso às instituições do Estado, o período oligárquico da República desempenharia papel nefasto na conformação de uma estrutura de classes assentada na diferenciação racial e sexual que, no período escravista, estava mascarada nas relações de produção. Mesmo que, como dissemos acima, a etapa final do escravismo possuísse um caráter cada vez mais racista - como forma de justificar a permanência da escravidão numa sociedade que, dado o salto demográfico, já dispunha suficientemente de "mão-de-obra excedente" -, tal caráter não se apresentava como uma contradição ideológica inerente ao modo de produção (fixado na oposição escravo-senhor, propriedade-proprietário) como se apresentará no espectro liberal-democrático de uma formação social burguesa. 


\section{BIBLIOGRAFIA}

BASSANEZI, Maria Silvia C. Beozzo. São Paulo do Passado: Dados Demográficos. São Paulo: Universidade Estadual de Campinas (Núcleo de Estudos de População), 1998. Vol.2(1854). Disponível em: http://www.nepo.unicamp.br/publicacoes/censos.php. Acesso em 20/01/2017; Vol.3 (1872); Vol.4 (1886);

BLACKBURN, Robin. Por que Segunda Escravidão? In: MARQUESE, Rafael; SALLAES, Ricardo (orgs.) Escravidão e capitalismo histórico no século XIX: Cuba, Brasil e Estados Unidos. Rio de Janeiro: Editora Civilização Brasileira, pp.13-54, 2016;

CHALHOUB, Sidney. Visões da Liberdade: uma história da última década da escravidão na Corte. São Paulo: Companhia das Letras, 2011.

FIABANI, Adelmir. Mato, Palhoça e Pilão: o quilombo, da escravidão às comunidades remanescentes (1532-2004). São Paulo: Ed. Expressão Popular, 430p, 2012.

FRAGOSO, João. Barões do Café e Sistema Agrário Escravista: Paraíba do Sul / Rio de Janeiro (1830-1888). Rio de Janeiro: Ed. 7Letras, 195p, 2013;

GOMES, Alessandra Caetano. Em Busca da Liberdade: as alforrias em duas regiões do sudeste escravista (1825-1888) São Paulo, Dissertação de Mestrado em História Econômica. Programa de Pós-Graduação em História Econômica, Universidade de São Paulo, 175p, 2008.

GORENDER, Jacob. O Escravismo Colonial. São Paulo: Editora Ática, 1980, 592p, 3.ed. Coleção Ensaios, N.29;

LAMOUNIER, Maria Lúcia. Agricultura e Mercado de Trabalho: Trabalhadores Brasileiros Livres nas Fazendas de Café e na Construção de Ferrovias em São Paulo, 1850-1890. Revista Estudos Econômicos. V.37, N.2, pp.353.372, 2007.

LUNA, Francisco Vidal \& KLEIN, Herbert S. Escravismo no Brasil. São Paulo: Edusp, 398p, 2010.

MARX, Karl. O Capital. Crítica da Economia Política. Vol.1. Livro Primeiro. São Paulo: Editora Nova Cultural, 485p, 1996.

MATOS, O. N. Café e ferrovias: a evolução ferroviária de São Paulo e o desenvolvimento da cultura cafeeira. São Paulo: Editora Alfa-Ômega, Sociologia e Política, 135p, 1974;

MARTINS, José de Souza. O Cativeiro da Terra. São Paulo: Editora Contexto, 288p, 2010.

MELLO, Pedro Carvalho de. Aspectos econômicos da organização do trabalho da economia cafeeira do Rio de Janeiro, 1850-88. Revista Brasileira de Economia, Vol.32, N.1, pp.19-67, 1978;

RIBEIRO, Darcy. As Américas e a Civilização. São Paulo: Cia das Letras, 527p, 2007. 6.ed; América Latina: a Pátria Grande. Rio de Janeiro: Editora Guanabara, 148p, 1986. 2.ed; O Povo Brasileiro: a formação e o sentido do Brasil. São Paulo: Companhia das Letras, 470p, 1995;

O Processo Civilizatório. Petrópolis: Editora Vozes, 257p, 1983. 7.ed; 
SAES, Décio. A Formação do Estado Burguês no Brasil - 1888-1891. Rio de Janeiro: Paz e Terra, 364p, 1990.

TOMICH, Dale; ZEUSKE, Michael. Introduction, the Second Slavery: Mass Slavery, WorldEconomy, and Comparative Microhistories. Review (Fernand Braudel Center), V.31, N.2, pp.91-100, 2008. Disponível em: www.jstor.org/stable/40241709. Acesso em 17-01-2017.

\section{NOTAS}

1. “Os plantadores norte-americanos puderam contar com o crescimento contínuo da população escrava. (...) Em 1820, havia 1,5 milhão de escravos nos Estados Unidos, 1,1 milhão no Brasil e provavelmente 350 mil em Cuba. Já em 1860 eram 4 milhões os escravos no Sul dos Estados Unidos, 1 milhão no Brasil e 400 mil em Cuba." (BLACKBURN, 2016, p.21) "Isto só pode ser entendido de acordo com a própria lei da população escrava, que devia induzir, como ocorreu, a emergência de regiões especializadas na criação e na exportação de escravos, o que determinou primacialmente o aumento vegetativo da população servil em seu conjunto. Com isso, não deixou de atuar a lei populacional, mas apenas exibiu uma das variantes tendenciais de sua atuação". (GORENDER, 1980, p.330.) 2. José de Souza Martins, dentre outros autores, mencionam a reimigração para a Argentina e o Uruguai como principal fator da não permanência dos imigrantes (principalmente os italianos) nas lavouras cafeeiras. Cf. MARTINS, J. O Cativeiro da Terra. 2010.

3. Esse fato já chamou a atenção recente da historiografia brasileira e está consideravelmente bem documentado. (LAMOUNIER, 2007)

4. Do ano de 1854 - ano da regulamentação da Lei de Terras - ao ano de 1886 - último ano da contagem de matrículas dos trabalhadores escravizados - a população brasileira elevou-se de 7 milhões e 686 mil para 13 milhões e 141 mil indivíduos, verificando um aumento de 70,97\%. A Província de São Paulo, no entanto, contempla, no mesmo período, um aumento percentual de 200,30 pontos, saltando de 345.638 habitantes para 1.036 .978 (1.102.454). Ainda que a participação relativa da população paulista no total da população brasileira tenha variado de $4,49 \%$ para $7,89 \%$, a contribuição real do crescimento demográfico de São Paulo para o total do país foi de $12,67 \%$. Isso significa que dos 5.455.000 indivíduos a mais que passam a figurar na estimativa populacional brasileira, São Paulo participa com 691.340 pessoas, daí a porcentagem de 12,67 pontos. Os dados apresentados foram obtidos ao somar os números apresentados por Odilon Nogueira de Matos nas páginas 39, 41, 43 e 44. (MATOS, 1974) Para a população brasileira, utilizamos o Anuário Estatístico Brasileiro de 1960, elaborado pelo IBGE, que contém uma estimativa de crescimento anual da população desde 1854 .

5. 0 abandono da lavoura e mesmo da província, bem como as naturalizações, ou simplesmente a passagem pelo porto de Santos para outras províncias podem explicar a discrepância assinalada.

6. A análise pormenorizada do "Gráfico 4" revela, ainda, o efeito contrarrestante da produção cafeeira não só na província de São Paulo, mas também nas demais províncias que tinham no café seu polo dinâmico, como é o caso do Rio de Janeiro e de Minas Gerais. 0 ano de 1885 marca tanto a Lei dos Sexagenários, quanto o aprofundamento da luta dos escravizados pela emancipação e o movimento abolicionista como um todo. A matrícula realizada entre 1886 e 1887 é a última antes da abolição e representa, principalmente para São Paulo, a força que o escravismo possuía na província, ao verificar uma queda de $30,03 \%$ do total de escravizados, enquanto Rio de Janeiro e Minas Gerais perfazem 49,41\% e 35,78\% em apenas um ano. Em números absolutos, Rio de Janeiro deixa de contar com 165.987 trabalhadores e trabalhadoras escravizados e Minas Gerais com 106.979. São Paulo, “apenas" 45.941, não atingindo nem 15\% do total de perda das três províncias 
somadas, mantendo-se muito próximo do seu patamar "ótimo" que permitiu a expansão da fronteira agrícola no último quartel do século XIX.

7. Aqui se associam as leis de "rigidez da mão-de-obra escrava" e da "população escrava", esta última que tende a sua redução constante. Essa associação explica a utilização permanente do escravizado ao longo de um ano inteiro - mesmo que o ciclo do café seja menor - na ampliação da fronteira agrícola, por exemplo.

8. É seguramente provável que, em realidade, a proporção de lavradores de "cor" seja maior que $34,32 \%$ enquanto que para os brancos lavradores esse percentual seja menor. Além disso, não discriminamos aqui os dados relativos aos trabalhadores dedicados exclusivamente à plantagem cafeeira, daqueles vinculados a outras plantações acessórias ao café e ao meio urbano.

9. Segundo a estimativa do Anuário Estatístico Brasileiro de 1960, o Brasil dispunha de uma população de 7.686.000 indivíduos em 1854. Em 1872, essa população já havia alcançado 10.298.000 pessoas. E, apenas 15 anos depois, atingia a cifra de 13.141.000. IBGE. Anuário Estatístico do Brasil. 1960.

10. “(...) através da reapropriação [saques, roubos, rapinas] no interior da produção escravista, o cativo obtinha bens por ele produzidos. Por sua vez a apropriação garantia aos quilombolas a obtenção de bens indispensáveis à própria sobrevivência, nos quadros da sociedade que se apropriava, através da violência de sua força de trabalho". (FIABANI, 2012, p.333)

\section{RESUMOS}

Neste artigo investigamos a relação da produção cafeeira com a sobrevivência do escravismo na segunda metade do século XIX, principalmente na província de São Paulo. Tal inquietação parte do combate que Jacob Gorender travou contra o mito de que os cafeicultores do Novo Oeste paulista seriam, além de 'capitalistas', abolicionistas (por promoverem a imigração e o trabalho livre em suas fazendas), provando, em verdade, que o trabalho escravizado permaneceu como opção prioritária para esses plantadores até a Abolição. Em decorrência, apontamos, em linhas gerais, a inevitabilidade de retomar a discussão sobre o movimento abolicionista e a luta dos escravizados como os principais responsáveis por colocar termo ao escravismo colonial.

In this paper we study the coffee production and survival of slavery relation during the second half of the 19th century, especially in the São Paulo province. This theme comes from Jacob Gorender's fight against the myth that coffe farmers in the "New West" of São Paulo were not only 'capitalists', but abolitionists (for promoting immigration and free labor on their farms), proving that enslaved labor remained a main option for these plantadores until Abolition. As a result, we approach the inevitability of getting back to discussing about the abolitionist movement and the struggle of the enslaved as responsible for putting "colonial slavery" to an end.

En este artículo investigamos la relación de la producción cafetera con la sobrevivencia del esclavismo en la segunda mitad del siglo XIX, principalmente en la província de San Pablo. El interrogante parte de la tesis presentada por Jacob Goren contra el mito de que los caficultores del nuevo oeste paulista serían, además de capitalistas, abolicionistas (por promover la inmigración y el trabajo libre en sus haciendas), lo que en realidad ocurrió, es que el trabajo esclavizado permaneció como opción prioritaria para esos hacendados hasta la abolición. En conclusión y en términos generales, es inevitable retomar la discusión sobre el movimiento 
abolicionista y la lucha de los esclavizados como los principales responsables por colocar fin a la esclavitud colonial.

Dans cet article, nous étudions les rapports entre la production de café et la survivance de l'esclavage, dans la deuxième moitié du XIXe siècle, principalement dans la province de São Paulo. Ces interrogations viennent du combat que Jacob Gorender a mené contre le mythe selon lequel les cultivateurs de café du Nouvel Ouest pauliste seraient plus que des «capitalistes abolitionnistes » (puisqu'ils favorisent l'immigration et le travail libre dans leurs propriété), en prouvant, au contraire, que le travail esclave est demeuré une option prioritaire pour ces planteurs, jusqu'à l'abolition. Par conséquent, nous soulignons, globalement, la nécessité de rouvrir le débat sur le mouvement abolitionniste et sur la lutte des esclaves, qui sont les principaux éléments en raison desquels l'on a mis un terme à l'esclavagisme colonial.

ÍNDICE

Palabras claves: plantación cafetera, esclavitud colonial, demografía

Mots-clés: Mots-clés : plantation de café, esclavagisme colonial, démographie

Keywords: coffe plantation, "colonial slavery", demography

Palavras-chave: plantagem cafeeira, escravismo colonial, demografia

\section{AUTOR}

PEDRO GUIMARÃES PIMENTEL

Colégio Pedro II. Departamento de História - Professor EBTT II; Doutorando do Programa de PósGraduação de Políticas Públicas e Formação Humana/UERJ. E-mail: pgp1988@gmail.com 